\title{
Light-dependent regulation of carotenoid biosynthesis in plants
}

\author{
Lorena Pizarro, and Claudia Stange \\ Laboratorio de Biología Molecular Vegetal, Facultad de Ciencias, Universidad de Chile, Las Palmeras 3425, \\ Casilla 653 Ñuñoa, Santiago, Chile
}

\begin{abstract}
L. Pizarro, and C. Stange. 2009. Light-dependent regulation of carotenoid biosynthesis in plants. Cien. Inv. Agr. 36(2):143-162. Carotenoids are colored terpenes synthesized in plants, algae and some yeasts and bacteria. In plants and algae, these lipophilic molecules exert functional roles in hormone synthesis, photosynthesis, photomorphogenesis and photoprotection. Additionally, they possess antioxidant properties and act as scavengers of reactive oxygen species. During the past decade almost all of the carotenogenic genes have been identified by molecular, genetic and biochemical approaches in the Arabidopsis thaliana model system. Carotenoid biosynthesis in plants is highly regulated, although all of the processes involved have not yet been identified. In this work, we review the mechanisms involved in the lightmediated regulation of carotenoid biosynthesis and the effect of light on the levels of expression of carotenogenic genes in higher plants. It has been shown that light induces the expression of carotenogenic genes during leaf and flower development and during fruit ripening. During these processes, photoreceptors are activated by light and translocated to the nucleus, leading to the induction of carotenogenic gene transcription. The molecular insight gained into the lightregulated expression of carotenoid genes will facilitate our understanding of the regulation of carotenoid biosynthesis. Manipulation of light signaling is also a genetic tool for altering color and nutritional value in plants, leading to the production of novel functional foods.
\end{abstract}

Key words: Carotenoid biosynthesis, gene expression, light regulation, plants.

\section{Introduction}

Carotenoids are lipid-soluble molecules of 40 carbons that are synthesized in a wide variety of photosynthetic and non photosynthetic organisms including plants, algae, some fungi and bacteria. Over 600 carotenoid structures are known, and these are divided into nonoxygenated molecules, designated as carotenes, and oxygenated carotenoids, referred to as xanthophylls (Figure 1). Carotenoids act as accessory pigments and have photoprotective

Received 28 September 2008. Accepted 22 December 2008.

Corresponding author: cstange@uchile.cl functions during photosynthesis (Takano et al., 2005, Telfer, 2005). They also protect cells from excessive light incidence through thermal dissipation and supply substrates for the biosynthesis of the plant growth regulator abscisic acid (ABA; Crozier et al., 2000). Carotenoids also play an important role in human nutrition and health, providing provitamin A, have anti-aging and anti-cancer activities and prevent age-related macular degeneration (Krinsky et al., 1994; Mayne, 1996; Rao and Rao, 2007; Sajilata et al., 2008). These properties have led to the development of various nutraceutical products containing carotenoids.

Due to the importance of carotenoids for plant and animal health, carotenoid biosynthesis reg- 
ulation has been studied for the last 40 years, both at the pure and applied levels, and nearly all carotenogenic genes in diverse plant species, algae, fungi and bacteria have been identified and characterized (Cunningham and Gantt, 1998; Cunningham et al., 2002; Howitt and Pogson, 2006). The knowledge generated from these studies has been used to improve the nutritional value of several plants, by engineering increased $\beta$-carotene and ketocarotenoid formation. (Shewmaker et al., 1999; Ye et al., 2000, 2005; Davuluri et al., 2005; Diretto et al., 2007; Aluru et al., 2008; Lamers et al., 2008).

Studies in regulation of carotenoid biosynthesis in flowers, fruits and leaves using plant models indicate that most carotenogenic genes are regulated at the transcriptional level. This transcriptional regulation has been the focus of a wide range of studies and reviews (Bramley, 2002; Cunningham, 2002; Shanker et al., 2003; Kato et al., 2004; Römer and Fraser, 2005; Howitt and Pogson 2006; Cloutault et al., 2008; Tanaka et al., 2008; Ito et al., 2009). On the other hand, light is a stimulus that activates a broad range of plant genes related to photosynthesis and photomorphogenesis. Carotenoids are required during photosynthesis in plants and algae, and, therefore, genes that direct the biosynthesis of carotenoids in these organisms are also regulated by light (von Lintig et al., 1997; Simkin et al., 2003; Woitsch and Römer, 2003; Briggs et al., 2007). However, the more recent advances in this area have not been compiled into a review of the mechanisms described to date that could modulate carotenoid gene expression in photoautotrophic organisms. As a result, we have prepared a timely manuscript that is aimed at a broad audience of pure and applied scientists and that synthesizes the most up-to-date literature in this fast-moving field of research.

Improving our knowledge about physiological processes in which light is implicated will help us to understand and improve the genetic modification processes of food crops and fruits and enhance the environmental adaptation of new transgenic plants. In this work, we review the mechanisms involved in the light-mediated regulation of carotenoid biosynthesis and the effect of light on the levels of expression of carotenogenic genes in higher plants.

\section{Biological functions of carotenoids}

In plants and algae, carotenoids are synthesized in the plastids, such as chloroplasts and chromoplasts. In chloroplasts, carotenoids as well as other pigments, such as chlorophyll $a$ and $b$, are localized and accumulate in the thylakoid membranes (Cunningham and Gantt, 1998), specifically near the reaction center of photosystem II in the light harvesting complexes (LHC). Carotenoids act as accessory pigments in the LHC, where they absorb light in a broader range of the blue spectrum (400$500 \mathrm{~nm}$ ) than chlorophyll, and they transfer the absorbed energy to chlorophyll $a$ during photosynthesis (Britton, 1995; Schmid 2008). In flowers and fruits, the presence of these pigmented molecules serves to attract pollinators and seed dispersal agents to the intense yellow, orange and red colors that they provide (Grotewold, 2006). Carotenes and xanthophylls also accumulate in lipid bodies or in crystalline structures in the chromoplasts of flowers, fruits and reserve roots (Vishnevetsky et al., 1999). Birds, fish and crustaceans utilize carotenoids for pigmentation and nutrition. For example, the cetocarotenoid astaxanthin is responsible for the orange color of salmon meat and lobster shells (reviewed in Grotewold, 2006). Carotenoids serve also as pigments in several ornamental plants, in the cosmetic and food industries (Klaüi and Bauernfeind, 1981) and are employed as poultry and fish feed additives (reviewed in Bjerkeng, 2000).

In addition, carotenoids are precursors in the biosynthesis of abscisic acid, a plant hormone involved in dormancy, maturation and differentiation of vegetal embryonic cells and in tolerance to abiotic stress (Crozier et al., 2000). Carotenoids also protect plant cells from photooxidative damage by quenching singlet oxygen produced from the chlorophyll triplet in the reaction center of photosystem II (Takano et al., 2005; Telfer, 2005). This antioxidant characteristic is a result of the conjugate bonds of the polyene chain, which permit the absorption of excess energy from other molecules (Britton, 1995; Britton et al., 1998; Nelson et al., 2003). Therefore, carotenoids provide photo-oxidative protection to cells and tissue against the harm- 
ful effects of singlet oxygen and lipid radicals and from the chlorophyll triplet (Stahl and Sies, 2003; Dall'Osto et al., 2006). Carotenoids also play a photoprotective role during excessive light incidence through thermal dissipation by means of the xanthophyll cycle, protecting the plant from photo-oxidative damage. This process occurs when excessive light increases the thylakoid $\Delta \mathrm{pH}$, activating the enzyme violaxanthin de-epoxidase (VDE), which converts violaxanthin to zeaxanthin. Zeaxanthin and protons may cause a conformational change in the LHC which favors thermal dissipation (reviewed in Niyogi, 1999).

Carotenoids are not synthesized by animals. Therefore, they must be ingested in the diet for the subsequent synthesis of related molecules such as provitamin A, retinal and retinoic acid, which play essential roles in nutrition, vision and cellular differentiation, respectively (Krinsky et al., 1994; Fraser and Bramley, 2004; Tapiero et al., 2004). Carotenoids have also been shown to delay the aging process due to their antioxidant properties (Mordi, 1993; Bartley and Scolnik, 1995). At the same time, oxidative damage, associated with several pathologies, including aging (Esterbauer et al., 1992), carcinogenesis (Breimer, 1990) and degenerative processes in humans, among others, can be reduced by ingestion of carotenoids (Snodderly, 1995; Mayne, 1996, Rao and Rao, 2007).

\section{Biosynthesis of carotenoids in plants}

Until the 1960's, research in carotenoid biosynthesis had been centered on characterizing the enzymes involved in the biosynthetic route of carotenoids, due to the fundamental role of these pigments in plants, humans (Cunningham and Gantt, 1998) and other animals. However, during the past 25 years, almost all genes, termed carotenogenic genes, that encode enzymes involved in the metabolism of carotenoids in diverse vegetal species, algae, fungi and bacteria, have been identified and characterized (Hirschberg et al., 1997; Cunningham and Gantt 1998; Cunningham et al., 2000; Cunningham, 2002; Naik et al., 2003; Lodato et al., 2004).
In plants, carotenogenic genes are encoded in the nuclear genome and the synthesized proteins are targeted as preproteins to the plastids, where they are post-translationally processed. Some carotenoid enzymes aggregate in multienzyme complexes in the stroma (isopentenyl pyrophosphate isomerase (IPI), geranylgeranyl pyrophosphate synthase (GGPPS) and phytoene synthase (PSY); Camara, 1993), while others are associated with the thylakoid membranes of these organelles (phytoene desaturase (PDS), zcarotene desaturase (ZDS), lycopene $\beta$-cyclase (LCYB) and lycopene $\varepsilon$-cyclase (LCYE); Cunningham and Gantt, 1998). GGPPS, in particular, is not distributed homogenously in the stroma; it is specifically concentrated in globules where carotenoids are accumulated (Cheniclet et al., 1992).

Carotenoid biosynthesis begins with the synthesis of the isoprenoid isopentenyl pyrophosphate (IPP; Figure 1), through two alternative pathways. These pathways are termed the mevalonate acetate route, which takes place in the cytosol, and the non-mevalonate route, which takes place in the plastids (Schwender et al., 1996; Lichtenthaler et al., 1997; Lichtenthaler et al., 1999). In the mevalonate acetate route, IPP is synthesized from 3 molecules of acetyl CoA by the enzyme hydroxymethyl glutaryl CoA reductase (HMGR). IPP molecules produced in the cytosol are used for the synthesis of sterols and ubiquinones, while IPP molecules synthesized in the plastids are precursors of carotenoids, chlorophylls, tocopherols and plastoquinones. (Figure 1, adapted from Cunningham and Gantt, 1998, and Naik et al., 2003). Crosstalk exists between the cytosolic and the plastidial pathways of isoprenoid biosynthesis, such that plastidial IPP can be exported to the cytosol (Rodríguez-Concepción and Gruissem, 1999; Laule et al., 2003).

In the non-mevalonate route (plastidial route), IPP is synthesized by condensing D-glyceraldehyde 3-phosphate with pyruvate, forming 1-deoxy-D-xylulose-5-phosphate (DOXP) (Rohmer, 1999; Shanker et al., 2003), a reaction catalyzed by DOXP-synthase (DXS). In subsequent steps catalyzed by DOXP reductoisomerase (DXR), hydroxymethylbutenyl diphosphate (HBMPP) synthase (HDS) and HBMPP reductase (HDR), 
DOXP is transformed to IPP by adjustment of the carbon skeleton (Lichtenthaler, 1999).

IPP molecules synthesized in the plastids are then isomerized to the allylic isomer dimethylallyl pyrophosphate (DMAPP) by means of IPP isomerase (IPI). Escherichia coli transformed with IPI cDNA of plant, algal and yeast origins showed an increase in the production of carotenoids (Kajiwara et al., 1997; Sun et al., 1998), suggesting that the IPI enzyme could participate in a limiting step in the biosynthesis of carotenoids, since its overexpression is sufficient to increase the amount of carotenoids.

Subsequently, DMAPP condenses with three molecules of IPP to generate a molecule of 20 carbons named geranylgeranyl pyrophosphate (GGPP), in a process involving GGPP synthase (GGPPS, in bacteria). In eukaryotes, the soluble DXS, IPI and GGPPS enzymes are located in the stroma of the chloroplast where they catalyze the formation of IPP, DMAPP and GGPP. These molecules are required for the synthesis of carotenoids and other isoprenoids such as gibberellins, tocopherols and chlorophylls (Cunningham, 2002).

The formation of the symmetrical 40-carbon phytoene from two molecules of GGPP is catalyzed by phytoene synthase (PSY, CRTB in bacteria) in a two-step reaction (Figure 1). Phytoene biosynthesis is the first reaction specifically related to the carotenoid biosynthesis pathway. The amino acid sequence of PSY from Arabidopsis thaliana, tomato (Solanum lycopersicum), algae and cyanobacteria resembles those of bacterial (CRTB) origin and shares a conserved prenyl-transferase domain (Cunningham and Gantt, 1998).

The biosynthesis of carotenoids continues with the desaturation of the colorless phytoene to produce the pink-colored trans-lycopene. These reactions are catalyzed by phytoene desaturase (PDS) that catalyzes the biosynthesis of $\zeta$-carotene, $\zeta$-carotene desaturase (z-CDS) which synthesizes pro-lycopene (7, 9, 9', 7'-tetra-cislycopene) and carotene isomerase (CRTISO) that transforms the pro-lycopene into lycopene (all-trans-lycopene) in plants (Isaacson et al., 2002; Park et al., 2002; Isaacson et al., 2004). In

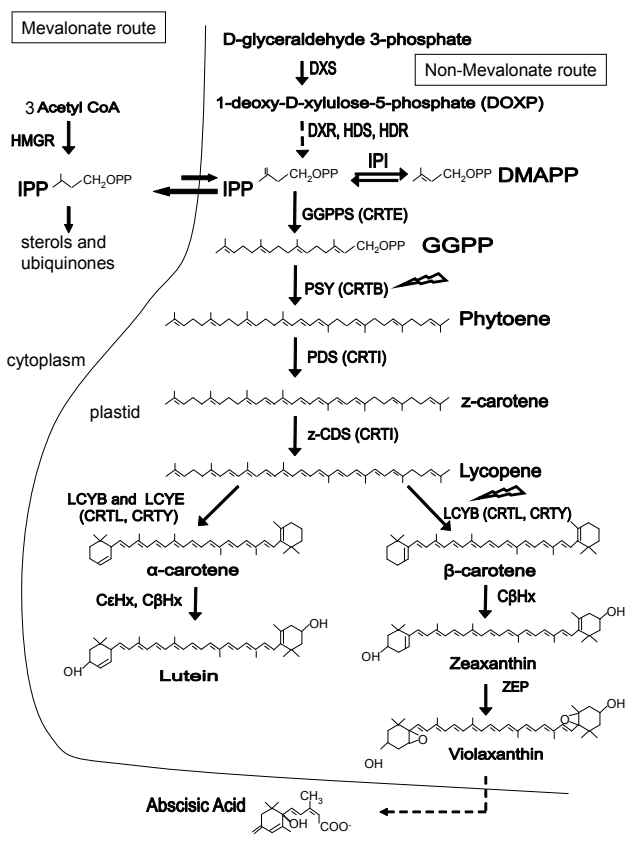

Figure 1. Schematic representation of carotenoid synthesis in prokaryotic and eukaryotic organisms. The isopentenyl pyrophosphate (IPP) molecule is synthesized via two pathways. The mevalonate route involves the synthesis of IPP via hydroxymethyl glutaryl CoA reductase (HMGR), whereas in the non-mevalonate route, IPP is synthesized by DOXP synthase (DXS), DOXP reductoisomerase (DXR), hydroxymethylbutenyl diphosphate (HBMPP) synthase (HDS) and HBMPP reductase (HDR). The other enzymes that participate in the biosynthesis of carotenoids and abscisic acid are: isopentenyl pyrophosphate synthase (IPI), geranylgeranyl pyrophosphate synthase (GGPPS), phytoene synthase (PSY), phytoene desaturase (PDS), $\mathrm{z}$-carotene desaturase (z-CDS), carotene isomerase (CRTISO), lycopene $\beta$ cyclase (LCYB), lycopene $\varepsilon$ cyclase (LCYE), $\beta$-carotene hydroxylase (C $\beta H x), \quad \varepsilon$-carotene hydroxylase $(\mathrm{C} \varepsilon \mathrm{Hx})$ and zeaxanthin epoxidase (ZEP). The name of the homologous enzyme in bacteria is written in parentheses. $\approx$ Indicates that light has an effect over carotenogenic gene expression.

leaves, the activity of CRTISO is substituted by photoisomerization of $\zeta$-carotene, neurosporene and prolycopene in the chloroplasts (Isaacson et al., 2002). Therefore, it has been hypothesized that the function of CRTISO in plants is to enable carotenoid biosynthesis in the dark, or in chromoplasts of nonphotosynthetic tissues such as fruits and roots (Isaacson et al. 2002, 2004). In almost all fungi and nonphotosynthetic bacteria, the enzymatic reactions that convert phytoene into lycopene are performed by a multifunctional enzyme encoded by the crtI gene (Misawa and Shimada, 1998). 
Subsequently, lycopene is transformed into different bicyclic molecules. It has been observed in plants and algae, that two enzymes participate in the cyclization of lycopene (Cunningham et al. 1996, 2007), whereas in bacteria a single protein carries out this function; CRTL in photosynthetic bacteria and CRTY in non-photosynthetic bacteria. In plants, one of these cyclases is lycopene- $\beta$-cyclase (LCYB), which converts lycopene into $\gamma$-carotene and subsequently to $\beta$-carotene. The other enzyme is lycopene- $\varepsilon$ cyclase (LCYE), which cyclizes one end of the lycopene molecule with an $\varepsilon$-ring ( $\delta$-caroteno); the other ring is formed by LCYB, thus producing $\alpha$-carotene (Cunningham et al., 1996). The $\beta$-carotene synthesized is utilized as a substrate for the enzyme $\beta$-carotene hydroxylase $(\mathrm{C} \beta \mathrm{Hx}$, CRTZ) to produce zeaxanthin, while the hydroxylation of $\alpha$-carotene by the $\varepsilon$-carotene hydroxylase $(\mathrm{C} \varepsilon \mathrm{Hx})$ and $\mathrm{C} \beta \mathrm{Hx}$ results in the formation of lutein. Using $A$. thaliana T-DNA knockout mutants, it has been shown that $\mathrm{C} \beta \mathrm{Hx}$ also possesses $\varepsilon$-hydroxylation activity and that it could act as a $\mathrm{C} \varepsilon \mathrm{Hx}$ enzyme (reviewed in Tian and Della Penna, 2004). Finally, abscisic acid is synthesized in the cytoplasm via a series of reactions subsequent to the epoxidation of zeaxanthin by zeaxanthin epoxidase (ZEP) (Figure1, Cunningham and Gantt, 1998; Cunningham, 2002; Naik et al., 2003).

\section{Carotenoid gene activation mediated by photoreceptors in plants}

The regulation of carotenoid biosynthesis has been studied in photosynthetic organs (leaves) and in non-photosynthetic organs (fruits, flowers, tubers and seeds) (Römer and Fraser, 2005; Howitt and Pogson, 2006). Almost all of these studies determined that light plays a considerable role in the induction of carotenogenic gene expression during the transition of etioplasts to chloroplasts (de-etiolation) and during fruit and flower development (Bramley, 2002; Römer and Fraser, 2005). During these processes, carotenogenic gene expression is mostly regulated at the transcriptional level and photoreceptors are involved in this process (Simkin et al., 2003; Woitsch and Römer, 2003). Plant photoreceptors include the family of phytochromes (PHYA-
PHYE) that absorb in the red and far red range as well as cryptochromes (Cry) and phototropins that absorb in the blue and UV-A range (Briggs and Olney, 2001; Franklin et al., 2005; Briggs et al., 2007). Phytochromes (PHY) are the most characterized type of photoreceptor and their photosensitivity is due to their reversible conversion between two isoforms: the Pr isoform that absorbs light at $660 \mathrm{~nm}$ (red light), resulting in its transformation to the Pfr isoform that absorbs light radiation at $730 \mathrm{~nm}$ (far red). Once Pr is activated, it is translocated to the nucleus as a $\mathrm{Pfr}$ homodimer or heterodimer (Huq et al., 2003; Matsushita et al., 2003; Sharrock and Clack, 2004; Franklin et al., 2005; Figure 2) where it accumulates in subnuclear bodies, called speckles (Nagy and Schafer, 2002; Nagatani, 2004). PHY acts as irradiance sensor through its active $\mathrm{Pfr}$ form, contributing to the regulation of growth and development in plants (Franklin et al., 2007), and a stable balance between these two isoforms regulates the light-mediated activation of signal transduction in plants.

The signal transduction machinery activated by PHY requires transcription factors such as PIF, HY5 and LAF1, which act in the de-etiolation process (Chattopadhyay et al., 1998; Ballesteros et al., 2001; Tepperman et al., 2001; Al-Sady et al., 2006). Recently, studies on phytochromeregulated gene expression by means of microarray analyses showed that many other transcription factors are also early over-expressed through PHYA and PHYB (Quail, 2007).

It has been shown that PHYA, but not PHYB, plays a role in the transcriptional induction of phytoene synthase (psy) in Arabidopsis (von Lintig et al., 1997), by promoting the binding of HY5 to white, blue, red and far red light responsive elements (LREs) located in its promoter (Figure 2). LREs are described to be sufficient to confer responsiveness to light in promoters that are not induced normally by light (RoaRodríguez, 2003). The most common type of LREs that are present in genes activated by light are the ATCTA element, and the G1 (CACGAG) and G2 motifs (CTCGAG) (von Lintig et al., 1997). PHYA, PHYB and CRY1, can also activate the Z-box (ATCTATTCGTATACGTGTCAC), another LRE present in light-inducible promoters (Yadav et al., 2002). 


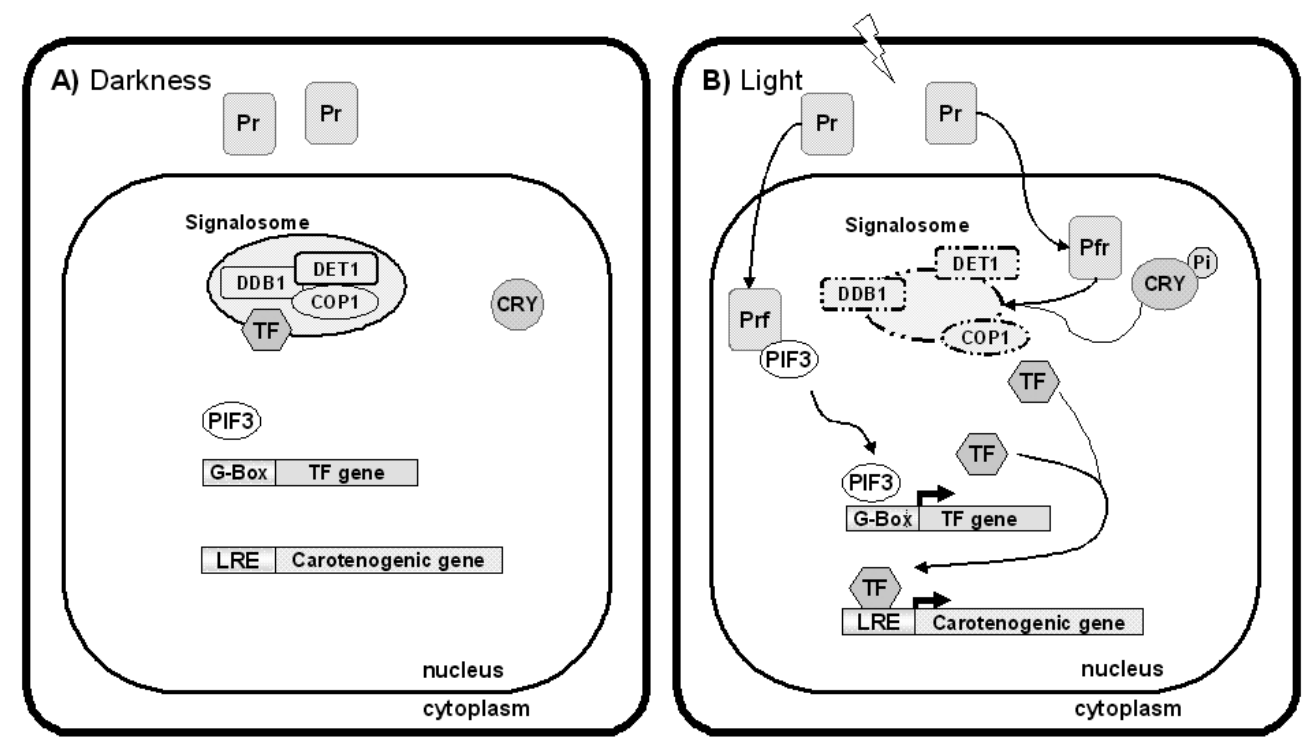

Figure 2. Model of the light-mediated activation of carotenogenic gene transcription in plants. A. On perception of light, the photoreceptors phytochrome (Pr inactive and Pfr active) and cryptochromes (CRY inactive and CRY-P active) are activated and translocated to the nucleus where they release the transcription factors (TF) from the signalosome (S). DET1, COP1 and DDB1 are some of the components of the signalosome. B. Direct phytochrome-mediated up-regulation of transcription factor expression. In both instances, free TF binds to light responsive elements (LRE) located in promoters, activating the transcription of carotenogenic genes.

The involvement of the b-zip transcription factor HY5 in tomato carotenogenesis was also proven with Lehy5 transgenic tomatoes that carry an antisense sequence or RNAi of the PHYA transcription factor-activated $h y 5$ gene. The transgenic Lehy5 antisense plants contained 24-31\% less leaf chlorophyll compared with non-transgenic plants (Liu et al., 2004), while immature fruit from Lehy5 RNAi plants exhibited an even greater reduction in chlorophyll and carotenoid accumulation.

The cryptochrome CRY, another type of photoreceptor, is also involved in carotenoid lightmediated gene activation. CRY1 localizes to the nucleus when plants are grown in light; however, during darkness it is exported into the cytoplasm (Guo et al., 1999; Yang et al., 2000; Schepens et al., 2004). CRY2, which belongs to the same family as CRY1, is localized to the nucleus of plant cells during both light and dark periods (Guo et al., 1999). Overexpression of Cry2 in tomato causes repression of lycopene cyclase genes, resulting in an overproduction of flavonoids and lycopene in fruits (Giliberto et al., 2005). In vivo assays showed that blue and UV-A light trigger the phosphorylation of CRY1 and CRY2 (Shalitin et al. 2002, 2003, Figure 2) and that PHYA phosphorylates cryptochrome in vitro (Ahmad et al., 1998). Therefore, phytochrome and cryptochrome signal transduction events are coordinated (Casal, 2000).

It has been reported that zeaxanthin acts as a chromophore of CRY1 and CRY2, leading to stomatal opening when guard cells are exposed to light (Winslow and Briggs, 1999). The blue/ green light absorbed by these photoreceptors induces a conformational change in the zeaxanthin molecule, resulting in the formation of a physiologically active isomer leading to the opening and closing of stomata (Talbott et al., 2002). Interestingly however, it has been demonstrated that this carotenoid can itself act as a photoreceptor. However, to date there are no other reports of zeaxanthin functioning as a photoreceptor.

Cryptochrome and PHY bind and inactivate COP1 through direct protein-protein contact (Wang et al., 2001; Seo et al., 2004, Figure 2). COP1 is a ring finger ubiquitin ligase protein associated with the signalosome complex involved in protein degradation processes via the $26 \mathrm{~S}$ 
proteasome (Osterland et al., 2000; Sullivan and Deng, 2003; Seo et al., 2003). During darkness, COP1 interacts with and triggers degradation of multiple transcription factors involved in light regulation, such as HY5 and HFR1 (Yang et al., 2001; Holm et al., 2002; Yanawaga et al., 2004). It has been shown that HY5 and HFR1 transcription factors co-localize with COP1 in nuclear bodies and are marked for post-translational degradation during repression of photomorphogenesis (Ang et al., 1998; Jung et al., 2005).

Several studies have proposed that light promotes conformational changes that result in a structural modification of COP1, inducing the release of transcription factors such as HY5, LAF1 and HFR1. Once these factors are released, they accumulate and bind to LREs located in the promoters of genes activated by light (Wang et al., 2001; Cashmore, 2003; Lin and Shalitin, 2003, Figure 2).

Liu et al. (2004), by means of Lecop1 RNAi transgenic tomatoes, determined that COP1 is also involved in carotenoid biosynthesis. These transgenic tomatoes have a reduced level of cop1 transcripts, and significantly higher leaf and fruit chlorophyll and carotenoid contents than the corresponding non-transformed controls.

Two other negative regulators of light-mediated gene expression, the UV-damaged DNA binding protein 1 (DDB1) and the de-etiolated-1 (DET1) factor, interact with COP1 and other proteins from the signalosome complex, leading to ubiquitination of transcription factors (Osterlund et al., 2000; Schroeder et al., 2002; Chen et al., 2004; Yanawaga et al., 2004). Posttranscriptional gene silencing of det1 leads to an accumulation of carotenoids in tomato fruits (Davuluri et al., 2005). In addition, HP-1 and HP-2 encode the tomato orthologs of DDB1 and DET1 in $A$. thaliana, respectively (Liu et al., 2004). Highly pigmented tomato mutants, named $h p-1$ and $h p-2$, display shortened hypocotyls and internodes, anthocyanin accumulation, strongly carotenoid colored fruits and an excessive response to light (Mustilli et al., 1999). As a consequence, $h p-2$ tomato plants that have a mutated version of HP-2 (DET1) produce high amounts of carotenogenic pigments (Mustilli et $a l ., 1999)$. Carotenoid biosynthesis in $h p-2 \mathrm{mu}-$ tants increased during light treatments, due to the decrease in ubiquitination of transcription factors mediated by the inactivation of the signalosome carried out by the phytochrome/cryptochrome transduction mechanisms.

Other mechanisms that regulate the expression of genes mediated by light include the direct interaction of Pfr with the helix-loop-helix transcription factor PIF3 (phytochrome-interacting factor). PIF3, once activated by Pfr, binds to G-box motifs present in various light-regulated promoters involved in the regulation of photomorphogenesis (Ni et al., 1998; Zhu et al., 2000, Figure 2). The involvement of other photoreceptors such as phototropins, CRY2 and phytochromes $\mathrm{C}$ and $\mathrm{E}$ in the activation of carotenogenic genes has not been evaluated. However, studies with phyC mutants revealed that PHYC is involved in photomorphogenesis throughout the life cycle of $A$. thaliana, playing a role in the perception of day length and acting with PHYB in the regulation of seedling de-etiolation in response to constant red light (Monte et al., 2003). Therefore, the possible involvement of these photoreceptors in carotenoid biosynthesis cannot be eliminated (von Lintig et al., 1997).

As mentioned previously, carotenoids carry out an essential function during photosynthesis in the antennae complexes of chloroplasts from green organs. Therefore, the regulation of the biosynthesis of these pigments in photosynthetic organs must be regulated by light (Cunningham, 2002) and associated with the production of chlorophyll (Averina, 1998; Woitsch and Römer, 2003; Eckhardt et al., 2004). Chlorophyll and carotenoid biosynthesis are associated, possibly because both processes are regulated by photoreceptors such as PHY (Mazzella et al., 1997; Woitsch and Römer, 2003). For example, white light treatments resulted in a moderate stimulation of the expression of ppox, which encodes protophorphirine oxidase (PPOX), an enzyme involved in chlorophyll biosynthesis, and simultaneously induced the expression of the carotenogenic genes lcy $\beta, c \beta h x$, violaxanthin de-epoxidase (vde) and zeaxanthin epoxidase (zep) (Woitsch and Römer, 2003).

As outlined above, regulation of light-mediated gene expression at the transcriptional level is the key mechanism controlling carotenogen- 
esis in the plastids. Nonetheless, Schofield and Paliyath (2005) demonstrated post-translational control of PSY mediated by phytochrome. It was observed that PSY activity is reversibly regulated by red and far red light as a consequence of phytochrome inactivation and activation, leading to an increase in PSY activity only under red light conditions (Schofield and Paliyath, 2005). Therefore, light, as sensed by photoreceptors, regulates carotenoid biosynthesis through transcriptional and post-transcriptional mechanisms.

Chlorophyll and carotenoid biosynthesis are also regulated indirectly by light through the redox potential generated during photosynthesis. In this process, plastoquinone acts as a redox potential sensor responsible for the induction of carotenogenic genes, indicating that the biosynthesis of carotenoids is under photosynthetic redox control (Jöet et al., 2002; Steinbrenner and Linden, 2003; Woitsch and Römer, 2003). Reactive oxygen species (ROS) produced through high light intensities and other environmental stresses increase the accumulation of the xanthophyll molecule astaxanthin in the green algae Haematococus pluvialis (Steinbrenner and Linden, 2001) and induce the synthesis of $\beta$-carotene in the unicellular algae Dunaliella salina and Dunaliella bardawil (Lamers et al., 2008). The presence of ROS causes an over expression of almost all carotenogenic genes in pepper (Capsicum annum) pericarp discs and leads to an accumulation of the xanthophyll capsorubin, which is necessary for chromoplast differentiation (Bouvier et al., 1998).

Carotenogenic gene activation induced by light in photosynthetic organs

The process of de-etiolation has been used to compare the levels of carotenoids and gene expression in dark-grown plants versus plants that were transferred to light after being in darkness. During de-etiolation of $A$. thaliana, the expression of ggpps and $p d s$ genes are relatively constant, whereas expression of the single copy genes $p s y$ and $h d r$ are significantly enhanced (von Lintig et al., 1997; Welsch et al., 2000; Botella-Pavía et al., 2004). Evidence indicates that the transcriptional activation of $p s y$ and $h d r$ is essential for the induction of carotenoid biosynthesis in green organs (Welsch et al., 2003; Botella-Pavía et al., 2004). During de-etiolation of tobacco (Nicotiana tabacum) and pepper, xanthophyll biosynthesis genes are transcriptionally activated after 3 to $5 \mathrm{~h}$ of continuous white-light illumination (Simkin et al., 2003; Woitsch and Römer, 2003).

In A. thaliana and tomato, it has been reported that $l c y \beta$ mRNA expression increases 5 times when seedlings are transferred from a low light to a high light environment (Hirschberg, 2001). With the onset of red, blue or white light illumination, significant induction of the expression of carotenogenic genes was documented in etiolated seedlings of tobacco, regardless of the light quality used (Woitsch and Römer, 2003). The expression level was dependent on phytochrome and cryptochrome activities. However, considerable differences in expression levels were observed with respect to the type of light used to irradiate the seedlings. For example, psy gene expression was significantly induced after continuous red and white light illumination, pointing to an involvement of different photoreceptors in the regulation of their expression (Woitsch and Römer, 2003). Li et al. (2008) determined that PHY is involved in mediating the up-regulation of $p s y 2$ gene expression during maize (Zea mays) seedling photoinduction. $L c y \beta, c \beta h x$ and $v d e$ are also induced upon red light illumination. However, zep shows similar transcriptional activation in the presence of red or blue light (Woitsch and Römer, 2003). Compared to normal carotenogenic gene induction mediated by light, the contribution of photo-oxidation to the amount of carotenoids produced in leaves is also important. Carotenoids are synthesized during light exposure but when light intensity increases from 150 to $280 \mu \mathrm{mol} \cdot \mathrm{m}^{-2} \cdot \mathrm{s}^{-1}$, the rate of photo-oxidation is higher than the rate of synthesis and carotenoids are destroyed, reaching a certain basal level (Simkin et al., 2003). The level of expression of some carotenogenic genes is also reduced following prolonged illumination at moderate light intensities (Woitsch and Römer, 2003).

During darkness, when photo-oxidation of carotenoids does not occur, the biosynthesis of carotenoids in leaves is stopped due principally 
to the very low level of expression of carotenogenic genes. In C. annum, $p s y, p d s, z d s$ and $l c y \beta$ genes are down-regulated (Simkin et al., 2003), while in A. thaliana the $p s y$ and $h d r$ are active in darkness only at basal levels (Welsch et al., 2003; Botella-Pavía et al., 2004). During de-etiolation of carrot leaves, the expression of psyl, $p d s$ and $z d s 2$ are down-regulated while $z d s 1$ is up-regulated (Stange et al., 2008).

The role of light in carotenoid biosynthesis during fruit ripening and flower development

Ripening is influenced by many factors, including developmental gene regulation, hormones, temperature, ethylene and light (Adams-Phillips et al., 2004). Light has been observed to affect carotenoid biosynthesis in a number of species during fruit ripening and flower development (Giovanonni, 2004; Adams-Phillips et al., 2004).

In tomato, the best plant model for evaluation of ripening, normal pigmentation of tomato fruits requires phytochrome-mediated light signal transduction, a process that does not affect other ripening characteristics, such as flavor (Alba et al., 2000). During tomato fruit ripening, carotenoid concentration increases 10- to 14-fold, mainly due to an accumulation of lycopene (Fraser et al., 1994). Lycopene and $\beta$-carotene are the most abundant carotenoids in ripe tomato fruits. Lycopene is converted to $\beta$-carotene by LCYB enzyme. Two lcy $\beta$ genes have been identified in tomato, $c y c \beta$ and $l c y \beta$. The first is responsible for carotenoid biosynthesis in chromoplasts whereas lcy $\beta$ performs this role preferentially in chloroplasts (Ronen et al., 1999). An increase in the synthesis of carotenoids is required during the transition from mature green to orange in tomato fruits. During this process, a coordinated up-regulation of $d x s$, $h d r, p d s$ and $p s y l$ is observed, while at the same time there is a decrease in the expression of $l c y \beta$, cyc $\beta$ and lcye (Fraser et al., 1994; Pecker et al., 1996; Ronen et al., 1999; Lois et al., 2000; Botella-Pavía et al., 2004). The down-regulation of lcy $\beta$ and $c y c \beta$ in tomato during ripening leads to an accumulation of lycopene in chromoplasts of ripe fruits (Pecker et al., 1996; Ronen et al., 1999). In contrast, in C. annuum, lcy $\beta$ is con- stitutively expressed during fruit development leading to an accumulation of $\beta$-carotene and capsanthin (Hugueney et al., 1995).

The HDR enzyme, involved in the synthesis of the plastidial IPP and DMAPP molecules, is considered a 'rate-determining' enzyme during the production of carotenoids and their precursors during tomato ripening (Botella-Pavía et al., 2004). High levels of isoprenoid intermediates after overexpression of DXS or HDR might affect the gene expression or enzyme activity of these and other enzymes of the pathway (Botella-Pavía et al., 2004). The psy gene also plays a considerable role in controlling carotenoid synthesis during fruit development and ripening (Giuliano et al., 1993; Fraser et al., 1999) and during flower development (Zhu et al., 2002, 2003). In tomato, two distantly-related genes, psyl and psy2 code for phytoene synthase, and the former was found to be transcriptionally activated only in petals and ripening tomato fruits after continuous blue and white light illumination (Welsch et al., 2000; Schofield and Paliyath, 2005; Giorio et al., 2008). Transgenic tomato plants expressing an antisense fragment of psyl showed a 50\% reduction in carotenoid levels in the fruit, while leaf carotenoids remained unaltered due to the expression of $p s y 2$ (Fraser et al., 1999). psy2 is expressed in all plant organs, preferentially in tomato leaves and petals (Giorio et al., 2008), but in green or ripe fruits it is only expressed at low levels (Bartley and Scolnik, 1993; Fraser et al., 1999; Giorio et al., 2008). psyl is also induced in the presence of ethylene, the major senescence hormone implicated in fruit ripening, indicating that PSY is a branch point in the regulation of carotenoid synthesis (Lois et al., 2000).

Evidence emphasizing the importance of light effectors during fruit ripening and carotenoid accumulation was obtained through post-transcriptional silencing of negative regulators of light signal transduction such as HP1 and HP2, as described above (Mustilli et al., 1999; Giovannoni, 2004; Liu et al., 2004). These highpigment tomato mutants ( $h p 1$ and $h p 2)$ have increased total ripe fruit carotenoids and are hypersensitive to light, but they show little change in other ripening characteristics, results similar to those observed in transgenic tomato plants 
overexpressing CRY (Davuluri et al., 2004; Giliberto et al., 2005).

Although light plays a key role in the regulation of carotenogenic gene expression during ripening in Solanaceous species, an up-regulation of carotenoid gene expression has also been reported in species of other families. For example, carotenogenic genes are induced during apricot (Kita et al., 2007) and citrus fruit (Kato et al., 2004) development and ripening, as well as during flower development of Gentiana lutea (Zhu et al., 2002) and other species (Schledz et al., 1996). Kita et al. (2007) described that psy, lcy $\beta, c \beta h x$ and zep transcripts accumulate in parallel with the synthesis of carotenoids during ripening in Japanese apricot (Prunus mume).

In juice sacs of Satsuma mandarin (Citrus reticulata), Valencia orange $(C$. sinensis) and Lisbon lemon $(C$. limon) the expression of carotenoid biosynthetic genes such as CitPSY, CitPDS, CitZDS, $\mathrm{CitLCYb}, \mathrm{CitHYb}$, and CitZEP increases during fruit maturation, co-ordinately with the synthesis of carotenes and xanthophylls (Kato et al., 2004). In $G$. lutea analysis of the expression of carotenogenic genes during flower development and in different plant organs indicated that psy was expressed in flowers concomitant with carotenoid synthesis but not in stems and leaves. Analysis of the expression of ggpps, $p d s$ and $z d s$ revealed that these transcripts accumulated in flowers and leaves but not in stems of G. lutea (Zhu et al., 2002).

Carotenogenic gene expression is not restricted to only the leaves, fruits and flowers. In root tubers such as potato, $\beta$-carotene and lutein accumulate (Nesterenko and Sink, 2003), and carotenoids are also present in amyloplasts of cereal seeds such as maize and wheat (Triticum aestivum; Panfili et al., 2004, see Howitt and Pogson 2006 for review). In roots of carrots (Daucus carota), high levels of carotenoids accumulate, especially $\alpha$ and $\beta$-carotene (Fraser and Bramley, 2004). Most of the carotenogenic genes in carrot have been identified, and their expression patterns were evaluated during the development of modified root in five cultivars (Clotault et al., 2008). The transcript accumulation of some carotenogenic genes correlates with the total carotenoid composition in the roots of colored cultivars (Yellowstone, Bolero and Nutrired) but not in the white cultivar. Recently, it was shown that light alters the morphology and development of modified carrot roots grown in the presence of light and differentially affects the accumulation of transcripts of several carotenoid genes in the Nantes cultivar (Stange et al., 2008). Therefore, light has a negative effect upon the development of a plant organ that normally develops in darkness and consequently, carotenogenic gene expression and carotenoid levels are altered.

\section{Discussion and biotechnological applications}

Given that carotenoids play an important roles in animals and plants, the cDNAs for most of the major enzymes related to carotenogenic metabolism have been cloned from bacterial, yeast, algal and plant sources in the past 25 years (Hirschberg et al., 1997; Cunningham and Gantt, 1998; Cunningham and Gantt, 2000; Cunningham, 2002; Naik et al., 2003). The knowledge generated to date has enabled investigators to understand and potentially control the carotenogenic pathway with the aim of genetically improving agronomic species with high nutritional value. One of the greatest achievements so far in the metabolic engineering of carotenoid synthesis has been the production of the so-called 'golden rice'. Targeting of the daffodil (Narcissus pseudonarcissus) or maize psy gene and crtI (phytoene desaturase and zcarotene desaturase from Erwinia uredovora) to chloroplasts under the control of the $35 \mathrm{~S}$ cauliflower mosaic virus promoter was sufficient to produce $\beta$-carotene in normally carotenoiddevoid rice endosperm, providing a staple food source rich in pro-vitamin A (Ye et al., 2000; Beyer et al., 2002; Schaub et al., 2005; Rai et $a l ., 2007)$. Other examples include the overproduction of $\beta$-carotene in potato (Diretto et al., 2007), tomato (Davuluri et al., 2005), canola (Brassica napus; Shewmaker et al., 1999), flax (Linum usitatissimum; Fijisawa et al., 2008) and maize (Aluru et al., 2008).

Although the carotenoid biosynthetic pathway has been successfully modified by genetic engineering, the complex molecular mechanisms involved in modulating carotenoid synthesis are still far from clear. Light is an important stimulus that induces expression of carotenoid 
genes in fruits, flowers and photosynthetic organs. The light signal is transduced to a chemical signal that is acted upon by chromoproteins acting as photoreceptors. Photoreceptors, such as phytochrome, participate in the regulation of the expression of many genes involved in the synthesis of xanthophylls in plants (Woitsch and Römer, 2003). The xanthophyll molecule zeaxanthin acts also as a photoreceptor. However, evidence describing the specific role of this pigment in the regulation of the synthesis of other carotenogenic genes is lacking, and it would be interesting to determine if this pigment exerts positive feedback over the expression of genes regulating its synthesis.

In contrast to leaves, in fruits, flowers, seeds, root tubers, and reserve roots, carotenoids accumulate in chromoplasts. In these plastids, carotenoids are stored in plastoglobuli, where they are more photo-stable than in chloroplasts (Merzlyak and Solovchenko, 2002). Therefore, photo-oxidation does not affect carotenoid content in these organs, even when they are exposed to light. The role of light in organ development and the synthesis of carotenoids in root tubers, seeds and reserve roots have yet to be investigated. Are the same genes, which are positively regulated by light in leaves and fruits, expressed in seeds, root tubers and reserve roots, or do plants have specific carotenogenic genes for each organ, such as was reported for $p s y$ and $l y c b$ in tomato? This question awaits further investigation.

Another mechanism related to light-regulated carotenoid biosynthesis is associated with the redox potential generated by the electron transport chain during photosynthesis. The plastoquinone pool in which the plastoquinone pool functions as a redox sensor (Steinbrenner and Linden 2003, 2001; Buchanan and Balmer, 2005). However, in plants it has been determined that only a few carotenogenic genes are controlled by the cellular redox state (Bouvier et al., 1998; Woitsch and Römer, 2003). In chromoplasts of Narcissus pseudonarcissus, PSY and PDS are regulated post-transcriptionally by the redox state of the membrane-bound electron acceptors (Welsch et al., 2000). These results suggest the presence of a complex regulation of carotenogenic gene expression mediated by both light and redox state, and more extensive studies are necessary to investigate these phenomena.

To date, many specific factors implicated in the regulation and transcriptional activation of carotenogenic genes have been identified. Studies on phytochrome-regulated gene expression through microarray analyses during initial exposure of $A$. thaliana seedlings to light showed that many transcription factors (HY5, CCA1, LHY, APRR9, APRR5, HYH, SPA1, PKS1) are up-regulated (Quail, 2007). The identified transcription factors have the ability to regulate multiple downstream target genes involved in the phytochrome-mediated signal transduction pathway (Quail, 2007) via two routes. One of these routes is the activation of transcription factors through their release from signalosome recruitment (Liu et al., 2004, Figure 2), while the other mechanism is the overexpression, at the transcriptional level, of the genes that encode these transcription factors (Quail, 2007, Figure 2). It has yet to be established whether the transcription factors described by Quail et al. (2007) play a role in the induction of carotenogenic genes. The use of RNAi transgenic plants would be an appropriate strategy to determine the role of some transcription factors in plant carotenogenesis.

It is interesting to note that COP1 and the signalosome were demonstrated to participate in modulating light-induced carotenogenic genes in yeast (Navarro et al., 2000) and in plants (Liu et al., 2004). Additionally, in vivo studies carried out in tomato confirmed that a COP1 protein is a negative regulator of carotenogenesis (Liu et al., 2004). This result supports the presence of an evolutionarily-conserved mechanism controlling the light-mediated development and synthesis of carotenoids in eukaryotic cells.

\section{Conclusions and future directions}

We have illustrated the role of light on carotenogenic gene regulation in photosynthetic (leaves) and non-photosynthetic organs (flower and fruits). Light acts as an inducer of photomorphogenesis and for carotenoid biosynthesis through photoreceptors and the activation of known transcription factors. 
Conventional studies focused on a specific gene or step in the carotenoid pathway combined with new technologies permitting an analysis of the entire pathway will be needed to understand the role of light upon carotenoid biosynthesis in diverse organisms. Transcriptome analysis will provide insights into regulatory branch points of the pathway, while proteomic studies could help to associate the protein/enzyme component profiles with the carotenoid content in plants.

Without doubt, aspects associated with the effect of light upon carotenoid biosynthesis regulation will be avenues warranting more intensive research efforts.

Many factors involved in carotenoid biosynthesis have been found by means of post-transcrip- tional gene silencing. Alternatively, the utilization of fruit-specific promoters (Corona et al., 1996), and light-positive and light-negative regulators (Davuluri et al., 2005) will allow the production of new varieties of plants with enhanced carotenoid accumulation specifically associated to fruits, without affecting the carotenoid biosynthesis regulation in non-target plant organs. This strategy could be used to develop different kinds of fruits with improved nutritional value, helping consumers to incorporate vitamin $\mathrm{A}$ in their diets.

\section{Acknowledgments}

Supported by grant Fondecyt 11080066 . We also thank Dr. Michael Handford for critical review of the manuscript.

\section{Resumen}

L. Pizarro y C. Stange. 2009. Efecto de la luz sobre la regulación de la biosíntesis de carotenoides en plantas Cien. Inv. Agr. 36(2):143-162. Los carotenoides son terpenos coloreados sintetizados en plantas, algas y algunas levaduras y bacterias. En plantas y algas poseen funciones esenciales durante la fotosíntesis, fotomorfogénesis, fotoprotección y en la síntesis de hormonas. Además poseen propiedades antioxidants neutralizando species reactivas de oxígeno. Durante la última década aproximadamente todos los genes carotenogénicos han sido identificados como resultado de estudios moleculares, genéticos y bioquímicos usando Arabidopsis thaliana como modelo vegetal. La biosíntesis de carotenoides es altamente regulada en plantas aunque todos los procesos involucrados no han sido completamente descritos. En esta revisión, mostramos los resultados más recientes sobre los mecanismos involucrados en la biosíntesis de carotenoides mediada por luz y el efecto de la luz sobre la expresión de genes carotenogénicos en plantas. Durante el desarrollo de hojas y flores y durante la maduración de frutos, la luz induce el aumento de la expresión de genes carotenogénicos. Durante estos procesos, los fotorreceptores son activados al captar la energía lumínica y translocados al núcleo induciendo de este modo la transcripción de los genes. Los estudios moleculares en torno a la expresión de genes carotenogénicos inducidos por luz permitirán facilitar el entendimiento de la regulación de la biosíntesis de carotenoides. Con este conocimiento y mediante la utilización de herramientas biotecnológicas se podrá generar alimentos funcionales con mayor contenido de vitamina A y antioxidantes.

Palabras clave: biosíntesis de carotenoides, expresión génica, regulación por luz, plantas. 


\section{References}

Adams-Philips L., C. Barry, J. Giovannoni. 2004. Signal transduction system regulating fruit ripening. Trends Plant Sci. 9: 331-338.

Ahmad, M., J.A. Jarillo, O. Smirnova, and A.R. Cashmore. 1998. The CRY1 blue light photoreceptor of Arabidopsis interacts with phytochromeA in vitro. Mol Cell 1: 939-948.

Al-Sady, B. W. Ni, S. Kircher, E., Schäfer, and P.H. Quail. 2006. Photoactivated phytochome induced short article rapid PIF3 phosphorilation prior to proteasome-mediated degradation. Mol. Cell 23: 439-446.

Alba, R. M.M. Cordonnier-Pratt, and L.H. Pratt 2000. Fruit localized phytochromes regulate lycopene accumulation independently of ethylene production in tomato. Plant Physiol. 123: 363-370.

Aluru M., Y. Xu, R. Guo, Z. Wang, S. Li, W. White, and S. Rodermel. 2008. Generation of transgenic maize with enhanced provitamin A content. J. Exp. Bot. 59:3551-3562.

Ang L.H., S. Chattopadhyay, N. Wei, T. Oyama, K. Okada, A. Batschauer, and X.W. Deng. 1998. Molecular interaction between COP1 and HY5 defines a regulatory switch for light control of Arabidopsis development. Mol. Cell 1:213-222.

Armstrong, G.A., A. Schmidt, G. Sandman, and J.E. Hearst. 1990. Genetic and biochemical characterization of carotenoid biosynthesis mutants of Rhodobacter capsulatus. J. Biol. Chem. 265: 8329-8338.

Averina N.G. 1998. Mechanism of regulation and interplastid localization of chlorophyll biosynthesis. Membr. Cell Biol. 12:627-643.

Ballesteros, M.L. C. Bolle, L.M. Lois, J.M. Moore, J.P. Vielle-Calzada, U. Grossniklaus, and N. Chua. 2001. LAF1, a MYB transcription activator for phytochrome A signaling. Genes Dev. 15:2613-2625.

Bartley, G., and P. Scolnik, 1993. cDNA cloning expression during fruit development and genome mapping of PSY2, a second tomato gene encoding phytoene synthase. J. Biol. Chem. 268:25718-25721.

Bartley, G., and P. Scolnik. 1995. Plant carotenoids: pigments for photoprotection, visual attraction and human health. Plant Cell 7:1032.

Beyer, P., S. Al-Babili, X. Ye, P. Lucca, P. Schaub, R.Welsch, and I. Potrykus. 2002. Golden Rice: introducing the beta-carotene biosynthesis path- way into rice endosperm by genetic engineering to defeat vitamin A deficiency. J. Nutr. 132:506S$510 \mathrm{~S}$.

Bjerkeng, B. 2000. Carotenoid pigmentation in salmonid fishes- recent progress. Pages 71-89 In: L.E. Cruz-Suarez, D. Ricque-Marie, M. TapiaSalazar, M.A. Olvera-Novoa, and R. CiveraCereceda (eds.), Avances en Nutrición Acuícola. V. Memorias del V Simposium Internacional de Nutrición Acuícola. Ciudad de Mérida, México.

Botella-Pavía, P., O. Besumbes, M. Phillips, L. Carretero-Paulet, A. Boronat, and M. RodríguezConcepción. 2004. Regulation of carotenoid biosynthesis in plants: evidence for a key role of hydroxymethylbutenyl diphosphate reductase in controlling the supply of plastidial isoprenoid precursors. Plant Cell 40:188-199.

Bouvier, F., R.A. Backhaus, and B. Camara. 1998. Induction and Control of Chromoplast-specific Carotenoid Genes by Oxidative Stress. J. Biol. Chem. 273:30651-30659.

Bramley, P., 2002. Regulation of carotenoid formation during tomato fruit ripening and development. J. Exp. Bot. 53:2107-2113.

Breimer, L. 1990. Molecular mechanisms of oxygen radical carcinogenesis and mutagenesis: the role of DNA base damage. Mol. Carcinog. 3:188197.

Briggs, W., and M. Olney. 2001. Photoreceptors in plant photomorphogenesis to date. Five phytochromes, two Cryptochromes, one phototropin, and one superchrom. Plant Physiol. 125:85-88.

Briggs, W., T.S. Tseng, H-T. Cho, T. Swartz, S. Sullivan, R. Bogomolni, E. Kaiserli, and J. Christie. 2007. Phototropins and their LOV domains: versatile plant blue-light receptors. J. Integr. Plant Biol. 49:4-10.

Britton, G. 1995. Regulation of carotenoid formation during tomato fruit ripening and development. J. Exp. Bot. 53:2107-2113.

Britton, G. 1998. Overview of carotenoid biosynthesis. Pages 13-147. In: G. Britton, S. Liaaen-Jensen, and H. Pfander (eds.), Carotenoids: Biosynthesis and Metabolism. Birkhauser Verlag. Basel, Switzerland.

Buchanan, B.B., and Y. Balmer. 2005. Redox regulation: A broadening horizon. Annu. Rev. Plant. Biol. 6:187-220.

Camara, B. 1993. Plant phytoene synthase complex: component enzymes, immunology, and biogenesis. Meth. Enzymol. 214:352-365.

Casal, J.J. 2000. Phytochromes, Cryptochromes, 
phototropin: Photoreceptor interaction in plants. Photochem Photobiol. 71:1-11.

Cashmore, A.R. 2003. Cryptochromes: enabling plants and animals to determine circadian time. Cell 114: 537-543.

Chattopadhyay, S., L.H. Ang, P. Puente, XW. Deng, and N. Wei. 1998. Arabidopsis bZIP protein HY5 directly interacts with light responsive promoters in mediating light control of gene expression. Plant Cell 10:673-683.

Chen, M., J. Chory, and C. Fankhauser. 2004. Light signal transduction in higher plants. Annu Rev Genet. 38:87-117.

Cheniclet, C., F. Rafia, A. Saint-Guily, A. Verna, and J.P. Carde. 1992. Localization of the enzyme geranylgeranylpyrophosphate synthase in Capsicum fruits by immunogold cytochemistry after conventional chemical fixation or quickfreezing followed by freeze-substitution. Labelling evolution during fruit ripening. Biol. Cell 75:145-154.

Clotault J., D. Peltier, R. Berruyer, M. Thomas, M. Briard, and E. Geoffriau. 2008. Expression of carotenoid biosynthesis genes during carrot root development. J. Exp. Bot. 59:3563-3573

Corona, V., B. Aracri, Kosturkova, G.E. Bartley, L. Pitto, L. Giorgetti, P.A. Scolnik, and G. Giuliano. 1996. Regulation of carotenoid biosynthesis gene promoter during plant development. Plant Journal 9:505-512.

Crozier, A., Y. Kamiya, G. Bishop, and T. Yolota. 2000. Biosynthesis of hormone and elicitor molecules. Pages 865-872. In: B. Buchanan, W. Gruissem, and R. Jones (eds.), Biochemistry and Molecular Biology of Plants. American Society of Plant Physiologist.

Cunningham, F.X., B. Pogson, Z.R. Sun, K.A. Mcdonald, D. Dellapena, and E. Gantt. 1996. Functional analysis of the $\beta$ and $\varepsilon$ lycopene cyclase enzymes of Arabidopsis reveals a mechanism for control of cyclic carotenoid formation. Plant Cell 8:1613-1626.

Cunningham. F.X., and E. Gantt. 1998. Genes and enzymes of carotenoid biosynthesis in plants. Annu Rev Plant Physiol. Plant Mol. Biol. 49:557-583.

Cunningham, F.X., and E. Gantt. 2000. Identification of multi-gene families encoding isopentenyl diphosphate isomerase in plants by heterologous complementation in Escherichia coli. Plant Cell Physiol. 41:119-123.

Cunningham, F.X. 2002. Regulation of carotenoid synthesis and accumulation in plants. Pure Appli. Chem. 74:1409-1417.
Cunningham F.X.m H. Lee, and E. Gantt. 2007. Carotenoid biosynthesis in the red alga Cyanidioschyzon merolae. Eukaryot. Cell 6:533-545.

Dall'Osto, L., C. Lico, J. Alric, G. Giuliano, M. Havaux, and R. Bassi. 2006. Lutein is needed for efficient chlorophyll triplet quenching in the major LHCII antenna complex of higher plants and effective protoprotection in vivo under strong light. BMC Plant Biol. 6:32-32.

Davuluri, GR., A. Van Tuinen, A.C. Mustilli, A. Manfredonia, R. Newman, D. Burgess, D.A. Brummell, S.K. King, J. Palys, J. Uhlig, H.M. Pennings, and C. Bowler. 2004. Manipulation of DET1 expression in tomato results in photomorphoenic phenotypes caused by post-transcriptional gene silencing. Plant J. 40:344-354.

Diretto G., R. Tavazza, R. Welsch, D. Pizzichini, F. Mourgues, V. Papacchiolo, P. Beyer, and G. Giuliano. 2006. Metabolic engineering of potato tuber carotenoids through tuber-spacific silencing of lycopene epsilon cyclase. BMC Plant Biol. 6:13.

Diretto G., S. Al-Babili, R. Tabaza, V. Papacchioli, P. Beyer, and G. Guiliano. 2007. Metabolic engineering of potato carotenoid content through tuber-specific overexpression of bacterial minipathway. PLoS ONE 4:e350.

Eckhardt U., B. Grimm, and S. Hörtensteiner. 2004. Recent advances in chlorophyll biosynthesis and breakdown in higher plants. Plant Mol. Biol. $56: 1-14$

Esterbauer, H., J. Gebiki, H. Puhl, and G. Jurgens. 1992. The role of lipid peroxidation and antioxidants in oxidative modification of LDL. Free Radic. Biol. Med. 13:341-391.

Franklin, K., V. Larner, and G. Whitelam. 2005. The signal transducing photoreceptor of plants. Int. J. Dev. Biol. 49:653-664.

Franklin, K., T. Allen, and G. Whitelam. 2007. Phytochrome $\mathrm{A}$ is an irradiance-dependent red light sensor. Plant J. 50:108-117.

Fraser, P.D., M.R. Truesdale, C.R. Bird, W. Schuch, and P.M. Bramley. 1994. Carotenoid biosynthesis during tomato fruit development. Plant Physiol. 105:405-413.

Fraser, P.D., J. Kiano, M. Truesdale, W. Schuch, and P. Bramley. 1999. Phytoene synthase-2 enzyme activity in tomato does not contribute to carotenoid synthesis in ripening fruit. Plant Mol. Biol. 40:687-698.

Fraser, P.D., and P. Bramley. 2004. The biosynthesis and nutritional uses of carotenoids. Prog. Lipid 
Res. 43:228-265.

Giliberto, L., G. Perrotta, P. Pallara, J.L. Weller, P.D. Fraser, P.M. Bramley, A. Fiore, M. Tavazza, and G. Giuliano. 2005. Manipulation of the blue light photoreceptor cryptochrome 2 in tomato affects vegetative development, flowering time, and fruit antioxidant content. Plant Physiol. 137:199-208.

Giorio, G., A.L. Stigliani, and C. D'ambrosio. 2008. Phytoene synthase genes in tomato (Solanum lycopersicum L.) - new data on the structures, the deduced amino acid sequences and the expression patterns. FEBS J. 275:527-535.

Giovannoni, J.J. 2004. Genetic regulation of fruit development and ripening. Plant Cell 16:S170S180.

Giuliano, G., G.E. Bartley, and P.A. Scolnik. 1993. Regulation of carotenoid biosynthesis during tomato development. Plant Cell 5:379-387.

Grotewold, E. 2006. The genetics and biochemistry of floral pigments. Annu. Rev. Plant Biol. 57:761-780.

Guo, H., H. Duong, N. Ma, and C. Lin. 1999. The Arabidopsis blue light receptor cryptochrome 2 is a nuclear protein regulated by a blue lightdependent posttranscriptional mechanism. Plant J. 13:279-287.

Hirschberg, J., M. Cohen, M. Harker, T. Lota, V. Mann, and I. Pecker. 1997. Molecular genetics of carotenoid biosynthesis pathway in plants and algae. Pure Appl. Chem. 69:2145-2150.

Hirschberg, J. 2001. Carotenoids biosynthesis in flowering plants. Curr. Opin. Plant Biol. 4:210218.

Holm, M., L.G. Ma, L.J. Qu, and X.W. Deng. 2002. Two interacting bZIP proteins are direct targets of COP1-mediated control of light dependent gene expression in Arabidopsis. Genes Dev. 16:1247-59.

Hugueney, P., A. Badillo, H.C. Chen, A. Klein, J. Hirschberg, B. Camara, and M. Kuntz. 1995. Metabolism of cyclic carotenoids: a model for the alteration of this biosynthetic pathway in Capsicum annuum chromoplast. Plant J. 8:417424.

Howitt, C.A., and B.J. Pogson. 2006. Carotenoid accumulation and function in seeds and non-green tissues. Plant Cell Environ. 29:435-445.

Huq E., B. Al-sady, and P.H. Quail. 2003. Nuclear translocation of the photoreceptor phytochrome $\mathrm{B}$ is necessary for its biological function in seedling photomorphogenesis. Plant J. 35:660-664.

Hundle, B., M. Alberti, V. Nievelstein, P. Beyer, and H. Kleinig. 1994. Functional assignment of Erwinia herbicola Eho 10 carotenoid genes expressed in Escherichia coli. Mol. Gen. Genet. 245:406-416.

Isaacson, T., G. Ronen, D. Zamir, and J. Hirschberg. 2002. Cloning of tangerine from tomato reveals a carotenoid isomerase essential for the production of carotene and xanthophylls in plants. Plant Cell 14:333-342.

Isaacson, T., I. Ohad, P. Beyer, and J. Hirschberg. 2004. Analysis in vitro of the enzyme CRTISO establishes a poly-cis-carotenoid pathway in plants. Plant Physiol. 136:4246-4255.

Ito M., Y. Yamano, C. Tode, and A. Wada. 2009. Arch.Biochem. Biophys. In press.

Joët, T., B. Genty, E.M. Josse, M. Kuntz, L. Cuornac, and G. Peltier. 2002. Involvement of a plastid terminal oxidase in plastoquinone oxidation as evidenced by expression of the Arabidopsis thaliana enzyme in tobacco. J. Biol. Chem. 277:31623-31630.

Jung, I.C., J.Y. Yang, H.S. Seo, and N.H. Chua. 2005. HFRA is target by COP1 E3 ligase for post-transcriptional proteolysis during phytochrome A signaling. Genes Develop. 19:593-602.

Kajiwara, S., P.D. Fraser, K. Kondo, and N. Misawa. 1997. Expresión of an isopentenyl dophosphate isomerase gene enhances isoprenoid biosynthesis. Biochem. J. 324:42-426.

Kato, M., Ikoma, Y., Matsumoto, H., Sugiura, M., Hyodo, and H., Yano, M. 2004. Accumulation of carotenoids and expression of carotenoid biosynthetic genes during maturation in citrus fruit. Plant Physiol. 134:824-837.

Kita, M., M. Kato, Y. Ban, C. Honda, H. Yaegaki, Y. Ikoma, and T. Moriguchi. 2007. Carotenoid accumulation in japanese apricot (Prunus mume Siebold \& Zucc.): Molecular analysis of carotenogenic gene expression and ethylene regulation. J. Agric. Food Chem. 55:3414-3420.

Klaüi, H., and J.C. Bauernfeind. 1981. Carotenoids as food color. Pages 48-319. In: J.C. Bauernfeind (eds.). Carotenoids as Colorants and Vitamin A Precursors. Academic Press. Inc. New York. USA.

Krinsky, N., X.D. Wang, T. Tang, and R. Russell. 1994. Cleavage of $\beta$-carotene to retinoid. Pages 21-28. in: Retinoids: From Basic Science to Clinical Applications (Livrea, MA and Vidali, G, Eds.) pp. 21-28, Birkhaüser, Basel, Alemania.

Laule, O., A. Furholz, H.S. Chang, T. Zhu, X. Wang, P.B. Heifetz, W. Gruissem, and M. Lange. 2003. 
Crosstalk between cytosolic and plastidial pathways of isoprenoid biosynthesis in Arabidopsis thaliana. Proc. Natl. Acad. Sci. USA 100:68666871.

Lamers P.P., M. Janssen, R.C. De Vos, R.J. Bino, and R.H. Wijffels. 2008. Exploiting carotenoid accumulation in Dunaliella salina for cell.factory applications. Trands Biotechnol. 26:631-638.

Li, F., R. Vallabhaneni, and L. Wurtzel. 2008. PSY3, a new member of the phytoene synthase gene family conserved in the poaceae and regulator of abiotic stress-induced root carotenogenesis. Plant Physiol. 146:1333-1345.

Lichtenthaler, H.K., J. Schwender, A. Dish, and R.M. Rohme. 1997. Biosynthesis of isoprenoids in higher plant chloroplasts proceeds via mevalonate-independent pathway. FEBS Lett. 400:271-274.

Lichtenthaler, H.K. 1999. The 1-deoxy-D-xylulose5-phosphate pathway of isoprenoid biosynthesis in plants. Annu. Rev. Plant Physiol. Plant Mol. Biol. 50:47-65.

Lin, C., and D. Shalitin. 2003. Cryptochrome structure and signal transduction. Annu. Rev. Plant Biol. 54:469-96.

Liu, Y., S. Roof, Z. Ye, C. Barry, A. van Tuinen, J. Vrebalov, C. Bowler, and J. Giovannoni. 2004. Manipulation of light signal transduction as a means of modifying fruit nutritional quality in tomato. Proc. Natl. Acad. Sci. USA 101:98979902

Lodato, P., J. Alcaíno, S. Barahona, P. Retamales, A. Jiménez, and V. Cifuentes. 2004. Study of the expression of carotenoid biosynthesis genes in wild-type and deregulates strains of Xanthophylomyces dendrorhous (ex.: Phaffia rodhozyma). Biol. Res. 37:83-93.

Lois, L., C. Rodriguez, F. Gallego, N. Campos, and A. Boronat. 2000. Carotenoid biosynthesis during tomato fruit development: regulatory role of 1-deoxy-D-xylulose 5-phosphate synthase. Plant J. 22:503-513.

Maoka T. 2008. Recent progress in structural studies of carotenoids in animals and plants. Arch. Biochem. Biophys. In press.

Matsushita, T., N. Mochizuki, and A. Nagatani. 2003. Dimers of the N-terminal domain of phytochrome B are functional in the nucleus. Nature 424:571-574.

Mayne, S. 1996. $\beta$-carotene, carotenoids and disease prevention in humans. FASEB J. 10:690-701.

Mazzella, M.A., T.M. Alconada, and J.J. Casal.
1997. Dual effect of phytochrome A on hypocotyl growth under continuous red light. Plant Cell Environ. 20:261-267.

Merzlyak, M.N., and A.E. Solovchenko. 2002. Photostability of pigments in ripening apple fruit: a possible photoprotective role of carotenoids during plant senescence. Plant Sci. 163:881-888.

Misawa, N., M. Nakagawa, K. Kobayashi, S. Yamano, Y Izawa, K. Nakamura, and K. Harashima. 1990 Elucidation of the Erwinia uredovora carotenoid biosynthetic pathway by functional analysis of gene products expressed in Escherichia coli. J. Bacteriol. 172:6704-6712.

Misawa N., and H. Shimada. 1998. Metabolic engineering for the production of carotenoids in noncarotenogenic bacteria and yeast. J. Biotechnol. 59:169-181.

Monte, E., J.M. Alonso, J.R. Ecker, Y. Zhang, X. Li, J. Young, S. Austin-Phillips, and P.H. Quail. 2003. Isolation and characterization of phyC mutants in Arabidopsis reveals complex crosstalk between phytochrome signaling pathways. Plant Cell 15:1962-80.

Mordi, R.C. 1993. Carotenoids: Functions and degradation. Chem. Ind. 3:79-83.

Mustilli, A., F. Fenzi, R. Ciliento, F. Alfano, and C. Bowler. 1999. Phenotype of tomato high pigment-2 mutants is caused for a mutation in the tomato homolog of Deetiolated1. Plant Cell 11:145-157.

Naik, P.S., A. Chanemougasoundharam, S.M.P. Khurana, and G. Kalloo, G. 2003. Genetic manipulation of carotenoid pathway in higher plants. Curr. Sci. 85:1423-1430.

Nagatani, A. 2004. Light-regulated nuclear localization of phytochromes. Curr. Opin. Plant Biol. 7:708-711.

Nagy, F., and E. Schafer. 2002. Phytochromes control photomorphogenesis by differentially regulated, interacting signaling pathways in higher plants. Annu. Rev. Plant Biol. 53:329-355.

Navarro, E., V. Ruiz-Peréz, and S. Torres-Martínez. 2000. Overexpressión of $\operatorname{crg} \mathrm{A}$ gene abolishes light requirement for carotenoid biosynthesis in Mucor circinelloides. Eur. J. Biochem. 267:800807.

Nelson, J.L., P.S. Bemstein, M.C. Schmidt, M.S. Von Tress, and E.W. Askew. 2003. Dietary modification and moderate antioxidant supplementation differentially affect serum carotenoids, antioxidant levels and markers of oxidative stress in older human. J. Nut. 133:3117-3123. 
Nesterenko, S., and K.C. Sink. 2003. Carotenoid profiles of potato breeding lines and selected cultivars. HortScience 38:1173-1177.

Ni M., J.M. Tepperman, and P.H. Quail. 1998. PIF3, a phytocrome interacting factor necessary for normal photoinduced signal transduction, is a novel basic helix-loop-helix protein. Cell 95:657-667.

Niyogi, K. 1999. Photoprotection Revisted: Genetic and Molecular Approaches. Annu. Rev. Plant Physiol. 50:333-359.

Osterlund, M.T., C.S. Hardtke, N. Wei, and X.W. Deng. 2000. Targeted destabilization of HY5 during light-regulated development of Arabidopsis. Nature 405:462-466.

Panfili, G., A. Fratianni, and M. Irano. 2004. Improved normal-phase high-performance liquid chromatography procedure for the determination of carotenoids in cereals. J. Agric. Food Chem. 52:6373-6377.

Park, H., S.S. Kreunen, A.J. Cuttriss, D. Dellapenna, and B.J. Pogson. 2002. Identification of the carotenoid isomerase provides insight into carotenoid biosynthesis, prolamellar body formation, and photomorphogenesis. Plant Cell 14:321-332.

Pecker, I., R. Gubbay, F.X. Cunningham, and J. Hirshberg. 1996. Cloning and characterization of the cDNA for lycopene $\beta$ cyclase from tomato reveal a decrease in its expression during tomato ripening. Plant Mol. Biol. 30:806-819.

Quail, P.H. 2007. Phytochrome-regulated gene expression. J. Integrat. Plant Biol. 49: 11-20.

Rai, M., K. Datta, V. Parkhi, J. Tan, N. Oliva, H.S. Chawla, and S.K. Datta. 2007. Variable T-DNA linkage configuration affects inheritance of carotenegenic transgenes and carotenoid accumulation in transgenic indica rice. Plant Cell Rep. 26:1221-1231.

Rao, A.V., and L.G. Rao. 2007. Carotenoids and human health. Pharmacological Res. 55:207-216.

Roa-Rodríguez, C. 2003. Promoters used to regulate gene expression. CAMBIA Intellectual Property. Canberra, Australia. Disponible en www.cambia. org

Rodríguez-Concepción, M., and W. Gruissem. 1999. Arachidonic Acid alters Tomato HMG expression and fruit growth and induces 3-Hydroxy-3 -Methylglutaryl Coenzyme A Reductase-independent lycopene accumulation. Plant Physiol. 119:41-48.

Rohmer, M. 1999. The discovery of a mevalonate independent pathway for isoprenoid biosynthesis in bacteria, algae and higher plants. Nat. Prod.
Rep. 16:565-574.

Römer, S., and P.D. Fraser. 2005. Recent advances in carotenoid biosynthesis, regulation and manipulation. Planta 221:305-308.

Ronen, G., M. Cohen, D. Zamir, and J. Hirshberg. 1999. Regulation of carotenoid biosynthesis during tomato fruit development: expression of gene for lycopene epsilon cyclase is down regulated during ripening and is elevated in the mutant delta. Plant J. 17:341-351.

Sajilata M.G., R.S. Singhal, and M.Y. Kamat. 2008. The Carotenoid Pigment Zeaxanthin-A Review. Comp. Rev. Food Sci. Food Safe. 7:29-49.

Schaub, P., S. Al-Babili, R. Drake, and P. Beyer. 2005. Why is golden rice golden (yellow) instead of red?.Plant Physiol. 138:441- 450.

Schepens, I., P. Duek, and C. Fankhauser. 2004. Phytochrome-mediated light signaling in Arabidopsis. Curr. Opin. Plant Biol. 7:564-569.

Schofield, A., and G. Paliyath. 2005. Modulation of carotenoid biosynthesis during tomato fruit ripening through phytochrome regulation of phytoene synthase activity. Plant Physiol. Biochem. 43:1052-1060.

Schroeder, D.F., M. Gahrtz, B.B. Maxwell, R.K. Cook, J.M. Kan, J.M. Alonso, J.R. Ecker, and J. Chory. 2002. De-etiolated 1 and damaged DNA binding protein 1 interact to regulate Arabidopsis photomorphogenesis. Curr. Biol .12:1462-1472.

Schledz, M., S. Albabili, J. Von Lintig, H. Haubruck, S. Rabbani, H. Kleinig, and P. Beyer. 1996. Phytoene synthase from Narcissus pseudonarcissus: functional expression, galactolipid requirement, topological distribution in chromoplasts and induction during flowering. Plant J. 10:781792.

Schmid, V. H. 2008. Light-harvesting complexes of vascular plants. Cell Mol. Life Sci. 65:36193639

Schwender, J., M. Seemann, H.T. Lichtenthaler, and M. Rohmer.1996. Biosynthesis of isoprenoids (carotenoids, sterols, prenyl side-chains of chlorophylls and plastoquinone) via a novel pyruvate/glcyeraldehydes 3-phosphate non-mevalonate pathway in the green alga Scenedesmus obliquus. Biochem. J. 316:73-80.

Seo, H.S., J.Y. Yang, M. Ishikawa, C. Bolle, M.L. Ballesteros, and N.H. Chua. 2003. LAF1 ubiquitination by COP 1 controls photomorphogenesis and is stimulated by SPA1. Nature 423:995-999.

Seo, H.S., E. Watanabe, S. Tokutomi, A. Nagatani, and N.H. Chua. 2004. Photoreceptor ubiquiti- 
nation by COP1 E3 ligase desensitizes phytochrome A signaling. Genes Dev. 18:617-622.

Shalitin, D., H. Yang, T.C. Mockler, M. Maymon, H. Guo, G.C. Guitelam, and C. Lin. 2002. Regulation of Arabidopsis cryptochrome 2 by blue light-dependent phosphorylation. Nature 417:763-767.

Shalitin, D., X. Yu, M. Maymon, T. Mockler, and C. Lin. 2003. Blue light-dependent in vivo and in vitro phosphorylation of Arabidopsis cryptochrome 1. Plant Cell. 15:2421-2429.

Shanker, V., R. Bhalla, and R. Luthra. 2003. An overview of the non-mevalonate pathway for terpenoid biosynthesis in plants. J. Biosci. 28:637646.

Sharrock, R., and T. Clack. 2004. Heterodimerization of type II phytochromes in Arabidopsis. Proc. Natl. Acad. Sci. USA 101:11500-11505.

Shewmaker C.K., J.A. Sheehy, M. Daley, S. Colburn, and D.Y. Ke. 1999. Seed-specific overexpresion of phytoene synthase: increase in carotenoids and other metabolic effects. Plant J. 20:401-412.

Simkin, A.J., C. Zhu, M. Kuntz, and G. Sandmann. 2003. Light-dark regulation of carotenoid biosynthesis en pepper (Capsicum annuum) leaves. J. Plant Physiol. 160:439-443.

Snodderly, D. 1995. Evidence for protection against age-related macular degeneration by carotenoids and antioxidant vitamins. Am. J. Clin. Nutr. 62:1448S-1461S.

Stahl W., and H. Sies. 2003. Antioxidant activity of carotenoids. Mol. Aspects Med. 24:345-351.

Stange C., P. Fuentes, M. Handford, and L. Pizarro. 2008. Daucus carota as a novel model to evaluate the effect of light on carotenogenic gene expression. Biol. Res. 41:289-301.

Steinbrenner, J., and H. Linden. 2001. Regulation of two carotenoid biosynthesis genes coding for phytoene synthase and carotenoid hydroxylase during stress-induced astaxanthin formation in the green alga Haematococcus pluvialis. Plant Physiol. 125:810-817.

Steinbrenner, J., and H. Linden. 2003. Light induction of carotenoid biosynthesis genes in the green alga Haematococcus pluvialis: regulation by photosynthetic redox control. Plant Mol. Biol. 52:343-356.

Sullivan, J.A., and X.W. Deng. 2003. From seed to seed: The role of photoreceptors in Arabidopsis development. Dev. Biol. 260:289-297.

Sun, Z., F.X. Cunningham, and E. Gantt. 1998. Differential expression pf two isopentenyl pyro- phosphate isomerases and enhanced carotenoid accumulation in a unicellular chlorophyte. Proc. Natl. Acad. Sci., USA. 95:11482-11488.

Takano, H., S. Obitsu, T. Beppu, and K. Ueda. 2005. Light-induced carotenogenesis in Streptomyces coelicolor A3(2): Identification of extracytoplasmic function sigma factor that directs photodependent transcription of the carotenoid biosynthesis gene cluster. J. Bacteriol. 187:1825-1832.

Talbott, L., G. Nikolova, A. Ortíz, I. Shmayevich, and E. Zeiger. 2002. Green light reversal of bluelight-stimulated stomatal opening is found in a diversity of plant species. Am. J. Bot. 89:366368.

Tanaka Y., N. Sasaki, and A. Ohyima. 2008. Biosynthesis of plants pigments: anthocyanins, betalains and carotenoids. Plant J. 54:733-749.

Tapiero H., D.M. Townsend, and K.D. Tew. The role of carotenoids in the prevention of human pathologies. Biomed Pharmacother. 58:100-110.

Telfer, A. 2005. Too much light? How beta-carotene protects the photosystem II reaction centre. Photochem. Photobiol. Sci. 4:950-956.

Tepperman, J.M., T. Zhu, H.S. Chang, X. Wang, and P.H. Quail. 2001. Multiple transcription-factor genes are early targets of phytochrome A signaling. Proc. Natl. Acad. Sci., USA 98: 9437-42.

Tian, L., and D. Dellapenna. 2004. Progress in understanding the origin and functions of carotenoid hydroxylases in plants. Arch. Biochem. Biophys. 430:22-29.

Vishnevetsky M., M. Ovadis, and A. Vainstein. 1999. Carotenoid sequestration in plants: the role of carotenoid associated proteins. Trends Plant Sci. 4: 232-235.

Von Lintig, J., R. Welsch, M. Bonk, G. Giuliano, A. Batschauer, and H. Kleinig. 1997. Light-dependent regulation of carotenoid biosynthesis occurs at the level of phytoene synthase expression and is mediated by phytochrome in Sinapsis alba and Arabidopsis thaliana seedlings. Plant J. 12:625634.

Wang, H., Ma, L.G., Li, J.M., Zhao, H.Y., and Deng, X.W. 2001. Direct interaction of Arabidopsis cryptochromes with COP1 in light control development. Science 294:154-158.

Welsch, R., P. Beyer, P. Hugueney, H. Kleinig, and J. von Lintig. 2000. Regulation and activation of phytoene synthase, a key enzyme in carotenoid biosynthesis, during photomorphogenesis. Planta 211:846-854.

Welsch, R., J. Medina, G. Giuliano, P. Beyer, and J. 
von Lintig. 2003. Structural and functional characterization of the phytoene synthase promoter from Arabidopsis thaliana. Planta 216:523-534.

Winslow, R., and J. Briggs. 1999. Blue-light photoreceptors in higher plants. Annu. Rev. Cell Dev. Biol. 15:33-62.

Woitsch, S., and S. Römer. 2003. Expression of xanthophyll biosynthetic genes during light-dependent chloroplast differentiation. Plant Physiol. 132:1508-1517.

Yadav, V., S. Kundu, D. Chattopadhyay, P. Negi, N. Wei, X.W. Deng, and S. Chattopadhyay. 2002. Light regulated modulation of Z-box containing promoters by photoreceptors and downstream regulatory components, COP1 and HY5, in Arabidopsis. Plant J. 31:741-753.

Yanawaga, J., J.A. Sullivan, S. Komatsu, G. Gusmaroli, G. Suzuki, J. Yin, T. Ishibashi, Y. Saijo, V. Rubio, S. Kimura, J. Wang, and X.W. Deng. 2004. Arabidopsis COP10 forms a complex with DDB1 and DET1 in vivo and enhances the activity of ubiquitin conjugating enzymes. Genes Dev. 18:2172-2181.

Yang, H.Q., J.Y. Wu, R.H. Tang, Y. Liu, and A. Cashmore. 2000. The $\mathrm{C}$ termini of Arabidopsis cryptochromes mediate a constitutive light response.
Cell 103:815-827.

Yang, H.Q., R.H. Tang, and A.R. Cashmore. 2001. The signalling mechanism of Arabidopsis CRY1 involves direct interaction with COP1. Plant Cell 13:2573-2587.

Ye, X., S. Al-Babili, A. Klot, J. Zhang, P. Lucca, P. Beyer, and I. Potrycus. 2000. Engineering the provitamin A ( $\beta$-carotene) biosynthetic pathway into (carotenoid-free) rice endosperm. Science 287:303-305.

Zhu, C.,S. Yamamura, H. Koiwa, M. Nishihara, and G. Sandmann. 2002. cDNA cloning and expression of carotenogenic genes during flower development in Gentiana lutea. Plant Mol. Biol. 48:277-285.

Zhu, C., Yamamura, S., Nishihara, M., Koiwa, H., and Sandmann, G. 2003. cDNAs for the synthesis of cyclic carotenoids in petals of Gentiana lutea and their regulation during flower development. Biochem. et Biophys. Acta 1625:305-308

Zhu Y., J.M. Tepperman, C.D. Fairchild, and P. Quail. 2000. Phytochrome B binds with greater apparent affinity than phytochrome A to the basic helix-loop-helix factor PIF3 in a reaction requiring the PAS domain of PIF3. Proc. Natl. Acad. Sci. USA 97:13419-13424. 
